UDK 528.932

\title{
CREATING AND ANALYSING THE DIGITAL TERRAIN MODEL OF THE SLIVOVO AREA USING QGIS SOFTWARE
}

\author{
Edon MALIQI ${ }^{1}$, Petar PENEV ${ }^{2}$, Faik KELMENDI ${ }^{3}$ \\ 1,2Photogrametry and Cartography, Geodesy, University of Architecture, Civil Engineering and Geodesy, \\ bul. "Hristo Smirnenski" 1, 1000, 1164 Sofia, Bulgaria \\ ${ }^{3}$ Kosovo Cadastral Agency, “Çlirimi”" No. 2, Ndërtesa e Arkivit / Kati II 5 1000, Prishtinë, Kosovo \\ E-mails: 1edon.maliqi@gmail.com (corresponding author); ${ }^{2}$ ppenev@gmail.com; \\ 3kelmendi.faik@gmail.com
}

Received 2 February 2017; accepted 16 August 2017

\begin{abstract}
The aim of the paper is developing the Digital Terrain Model (DTM in the further text) through QGIS software. In order to accomplish intention of the paper will test some of the methods and techniques that are widely known in nowadays and those are supported by QGIS software - an open source software. And those methods named TIN and GRID. For showing complexity on the study area will analyse some features or characteristics of terrain in the created DTM. All of these methods and techniques will be applied in QGIS. In general, the QGIS software has rich methodology for creation, intepretation, visualization and analysing the geo-spatial data and the DTM in particular.
\end{abstract}

Keywords: QGIS software, DTM, TIN, GRID, Slivovo area, analyse.

\section{Introduction}

The concept of creating digital terrain models of the terrain is relatively recent and the term Digital Terrain Model (DTM) is generally attributed to two American engineers at the Massatchusetts Institute of Technology during the late 1950s. The definition they coined then was: "a DTM is simplify a statistical representation of the continous surface of the ground by a large number of selected points with known X, Y, Z coordinates in an arbitrary coordinate field (El-Heimy et al. 2005). DTM consists of an organised set of information about the planimetric position and altitude of points describing the spatial configuration of relief structures and facilitating area reconstruction in new points (Smuleac et al. 2012). Digital terrain modelling encompases the following general tasks: generation, manipulation, interpretation, visualization and application (Weibel, Heller 1991). A DTM may be modified by model manipulation procedures as follow (Fig. 1) (Weibel, Heller 1991):

\section{The study area}

The study area is located in north-east of Kosovo centered on $42^{\circ} 35^{\prime} 51^{\prime \prime} \mathrm{N}$ and $21^{\circ} 18^{\prime} 42^{\prime \prime} \mathrm{E}$. The name of studing area is Slivovo. The area that will create the DTM is 200 hectares and the bounding coordinates ( $\mathrm{Y}$ and $\mathrm{X}$ ) in four corners of area according the Kosovo coordinate system, known as KosovaRef01 are: 7526138.720, 4718910.351; 7526918.720, 4717928.190;

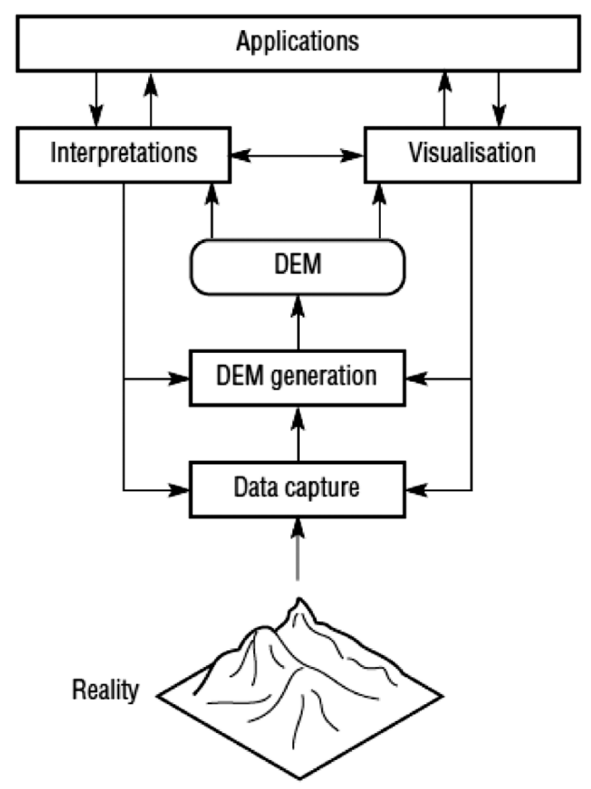

Fig. 1. The main tasks of DTM 


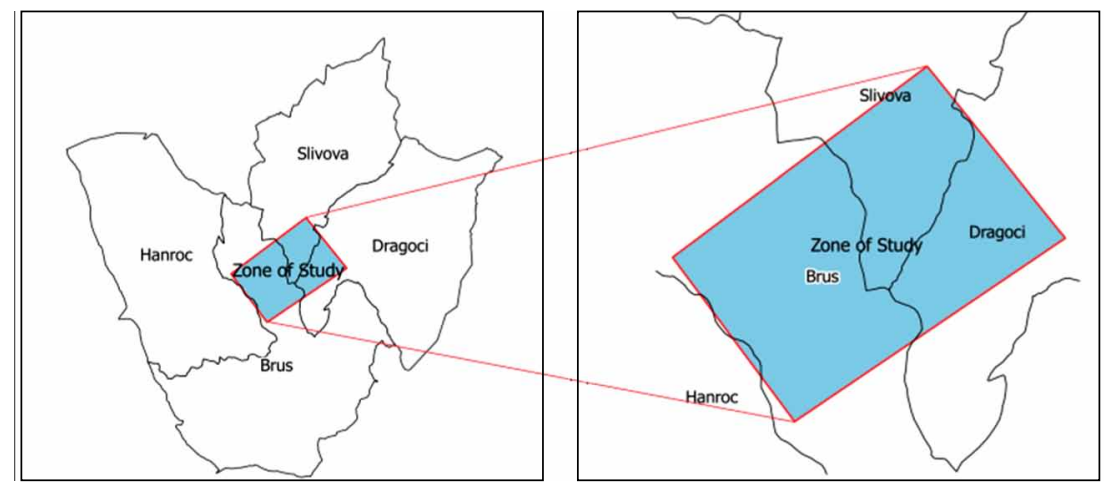

Fig. 2. Map of study area (Slivovo)

7525388.820, 4716879.455; 7524698.660, 4717818.368 .

This area is located in four cadastral zones that are part of two municipalities (Pristina and Lipian). The Slivovo terrain is characterized with lowlands and heightlands so it is very interesting terrain for creating and analysing of the DTM. The following Figure (Fig. 2) shows the position and shape of the study area named Slivovo.

\section{Modelling of terrain}

\subsection{QGIS software}

Quantum GIS, or QGIS as it is called today, is an open source GIS founded by Gary Sherman in 2002. Today QGIS is used by thousands of people all around the world and is increasingly becoming a viable alternative to proprietary desktop GIS software. QGIS can be downloaded for free and runs on most operating systems. (Osterman 2014). When editing maps QGIS provides the user with several functions. This includes, for example, digitizing of vector features, the possibility to add and remove points, lines and polygons from the existing data and various symbol choices (Osterman 2014). For developing the DTM of Slivovo area is used version 2.18 of QGIS, it is useful version for manipulating and analysing of the geo-spatial data also it supports methods and techniques of creating, interpolating and analysing or interpreting the DTM. Some of these options are impelmented and tested in the following sub-chapters. The following figure (Fig. 3) is icon of QGIS software.

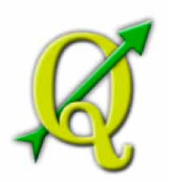

Fig. 3. Icon of QGIS

\subsection{Source data}

There are five main sources of the elevation data for DTM: ground surveys, airborne photogrammetric data capture, existing cartographic surveys (e.g. topomaps), airborne laser scanning and stereoscopic or radar-based satellite imagery (Hengel et al. 2003). To fulfill the aim of this paper is selected the groung survey technique of collecting the source data from the field. The measurements are realized with GPS eqquipment (Leica and Sokkia) based on KOPOS (Kosovo Positioning System) as part of GNSS (Global Navigation Satellite System) family. From the field are captured Y, $\mathrm{X}$ coordinate and $\mathrm{h}$ (ellipsoidal height) of points determined by GPS. These measurements are developed a few days. There are a big number of points collected in the field with positional accuracy $\pm 2 \mathrm{~cm}$ and vertical accuracy $\pm 4 \mathrm{~cm}$ and density approximately every $5 \mathrm{~m}$. These are the appropriate data for creating of the DTM. The gathered data from the field then are processing and filtering in the office. The reference coordinate system used for measuring points in the field is Kosovo coordinate system, known as KosovaRef01. The parameters of Kosovo coordinate system (KosovaRef01) are given in the following Table 1.

Table 1. Parameters of KosovaRef01

\begin{tabular}{|l|l|}
\hline Datum & ETRS89 \\
\hline Ellipsoid & GRS80 \\
\hline Map projection & Gaus-Krugger \\
\hline Prime meridian & Greenwitch \\
\hline Central meridian & $21^{\circ} \mathrm{E}$ \\
\hline Scale factor & 0.9999 \\
\hline False easting & $7500000 \mathrm{~m}$ \\
\hline Prime parallel & Equator \\
\hline False northing & $0 \mathrm{~m}$ \\
\hline origin of heights & Trieste-Molo Sartorio \\
\hline
\end{tabular}




\subsection{Methodology}

In general are known two main methods for creating of the DTM: TIN and GRID. The digital terrain model for Slivovo area will create with both of them in order to show and analyse the characteristics of the digital surface created in this paper. QGIS software exactly last version 2.18 provides and supports creating of the DTM based on TIN and GRID methods. Third, will use contour lines method for creating of digital model of the Slivovo which model will create based on TIN. But the intention of the paper is creating of the DTM based in heights above geoid not heights above ellipsoid. To achieve this intention, so the DTM of the orthometric heights (not ellipsoidal heights) requires conversion of ellipsoidal heights into orthometric heights. First is required to calculate the difference between ellipsoid and geoid in that area (Slivovo), known as geoid undulation because Kosovo does not have defined the national vertical datum yet. The equation that links these height measurements is:

$$
h(\mathrm{GPS})=H(\text { leveling })+N
$$

or

$$
H \text { (leveling) }=h(\text { GPS })-N \text {, }
$$

where: $N$ - geoid undulation, $h$ - heights above ellipsoid, $H$ - heights above geoid (orthometric heights).

Based on principle of above equation is used a technique for transformation of ellipsoidal height into local orthometric height, this technique called "Two Step" transformation model and is developed by Leica Geosystem, which is based in control points surrounding within the project area. In the generated report of
"Two Step" transformation model of this paper, from benefited results in the report we can conclude that geoid undulation in the particular area (Slivovo) is $-45.58 \mathrm{~m}$. Now are known all elements for continuing toward the intention of the paper, exactly creating the digital terrain model of Slivovo. The following figure (Fig. 4) show graphical overview of transfomation model generated in the report.

\subsection{TIN}

The triangulated irregular network (TIN) model is significant alternative to the regular raster of a DTM and has been adopted by numerous GIS and automated mapping and computer packages (El-Heimy et al. 2005). In a TIN model, the sample points are connected by lines to form triangles and within each triangle the surface is usually represented by a plane. The surface will be continous. As each triangle's surface would be defined by the elevations of the three corner points (El-Heimy et al. 2005).

Using QGIS's commands after are imported measured points in the field to QGIS workspace is created TIN surface exactly digital terrain model by TIN method for Slivovo area. The quality of TIN is high because density of points used are in the enjoyable distance. There are a big number of triangles with different area and shape. Based on TIN can conclude that Slivov area has different height from lowest $710 \mathrm{~m}$ and heighest $1000 \mathrm{~m}$. In the following figures (Fig. 5): a) are shown triangles of Slivovo terrain; b) is shown DTM by TIN method.

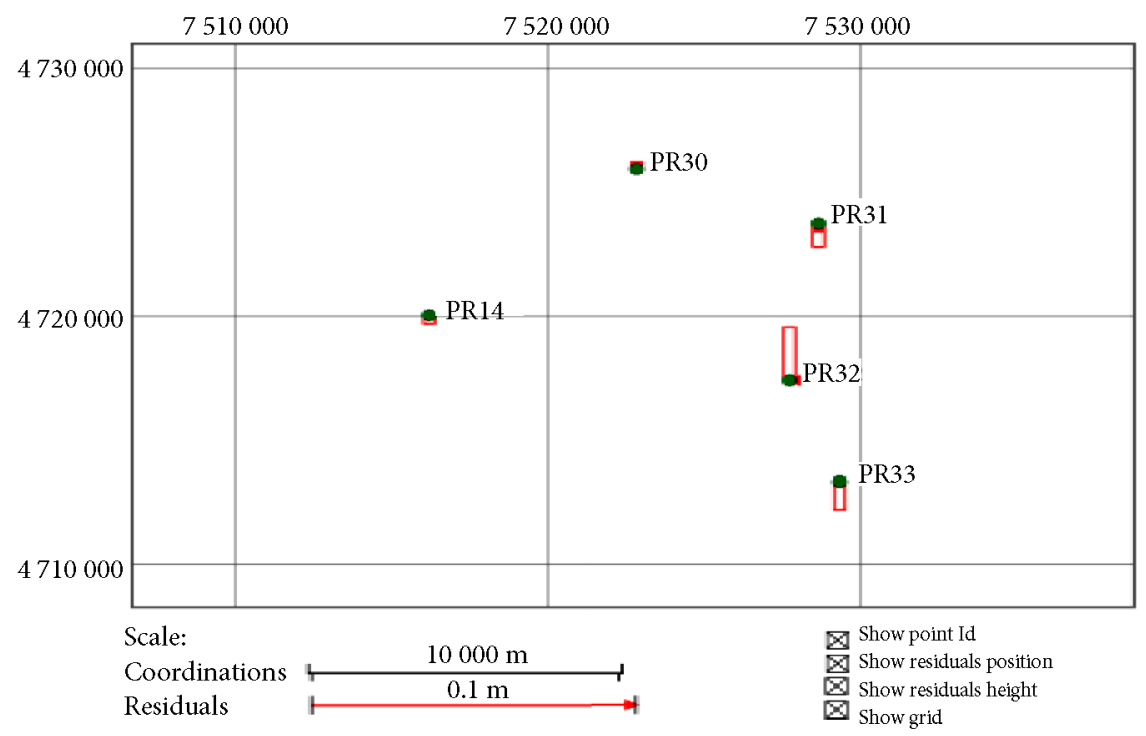

Fig. 4. Graphical overview of heights transfomation model 


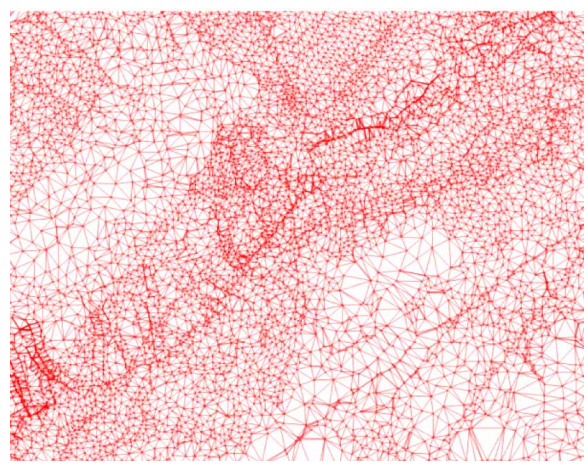

a)

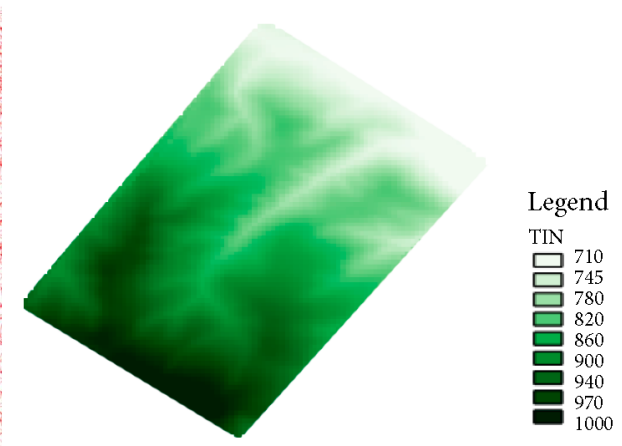

b)

Fig. 5. a) Triangles; b) DTM generated by TIN

\subsection{GRID}

Rectangular grid is one of the simplest ways of representing the DTM, the terrain surface is represented as a set of elevations for points regularly distributed on the $\mathrm{x}$ and $\mathrm{y}$ coordinates ( $\mathrm{Hu} 2013$ ). The simplicity of algorithms is the advantage of the grid structure. Regular grids cannot be adapted to the complexity of the terrain surface. Thus, an excessive number of data points are needed to represent the terrain by interpolating to acquire a certain level of accuracy of the terrain (Hu 2013). GRID surface of Slivovo area is created with dimensions $3 \times 3 \mathrm{~m}$, respectively with spatial resolution $3 \mathrm{~m}$. Since the collected coordinates are not regularly points it was impossible developing the GRID surface from source points. In order to solve this intention are combined some methods that supports QGIS software and finally is realized creation of GRID. The resolution above mentioned is appropriate for providing the real view of Slivovo area. Extreme quotes of this GRID are $712 \mathrm{~m}$ and $996 \mathrm{~m}$. Below are appeared regularly points and GRID (Fig. 6a and b).

\subsection{Visualization}

Visualization plays significant role in the DTM. In general Visualization has two main goals: first is interactive visualization which helps the user explore digital surface and second is static visualization which use for comparing results. We have used following forms of visualization in the next sub-chapters for the DTM of Slivovo area.

\subsubsection{Contour lines}

Contour lines use for representing the elevation of the terrain. It is mostly used techniques for displaying relief. A disadvantage of this form is that they could not show perspective view of terrain. For Slivov area are created two kinds of contour lines supported by QGIS software:

- contour lines with equidistance $10 \mathrm{~m}$ (Fig. 7a). - contour lines with equidistance $5 \mathrm{~m}$ (Fig. 7b).

\subsubsection{Hillshading}

Hillshading are based to a specified azimuth and altitude of the sun (light). Also for Slivovo area is created the digital surface based on hillshading technique.

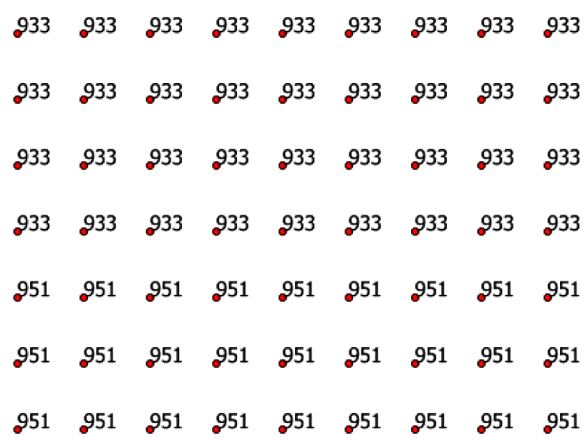

a)

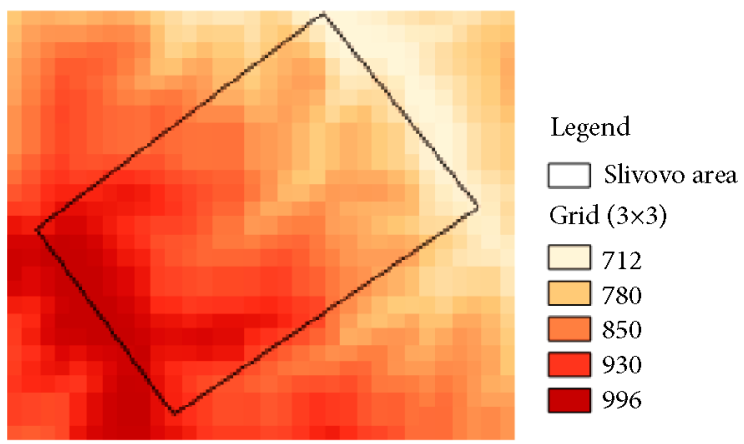

b)

Fig. 6. a) Regularly points for GRID; b) GRID of Slivovo area 
In the paper is realized this kind of visualization for two methods (TIN and GRID). The given elements of hillshading in QGIS software are: azimuth of the light and the altitude of the light.We realized hillshading by TIN method with this value; azimuth of the light $280^{\circ}$ and the altitude of the light $62^{\circ}$ (Fig. 8a). And is realized hillshading by GRID method with this value; azimuth of the light $300^{\circ}$ and the altitude of the light $55^{\circ}$ (Fig. 8b). These different values are used to see this techniqe of visualization in the best way with different source of light and azimuth and finally we evaluate that hillshading relief created is very qualitative.

\subsubsection{Perspective view}

QGIS software offers a big number of plugins that we can install from web. One of them is "QGIS2THREEJS" plugin, in this plugin you can view $3 \mathrm{D}$ objects in your web browser (you need a web browser which supports WebGL). In this way is appeared Slivovo area in the persepcetive view based on "QGIS2THREEJS" plugin. The following figure (Fig. 9) is perspective view of the Slivovo area.

\subsection{Analysis and interpretation}

From the paper could be concluded that the Slivovo area is characterisric terrain which include interesting elements of terrain. We have different shape and size of triangles created by TIN. Extreme quotes by TIN are $710 \mathrm{~m}$ and $1000 \mathrm{~m}$. By GRID method we have extreme quotes that are $712 \mathrm{~m}$ and $996 \mathrm{~m}$. So can conclude that it $i$ the same result and it is a little bit different comparing on two methods. GRID surface is with resolution $3 \mathrm{~m}$ and it provide the correct and real view of Slivovo area. For Slivovo area is calculated slope with two methods: percentage and grade supported by TIN of GIS software. This terrain has slope between $5 \%$ to $58 \%$ or $3^{\circ}$ to $30^{\circ}$. These calculations are based on DTM generated on the paper. Following figures shown visualized slopes of Slivovo area. In other hand is generated aspect of Slivovo area. Aspect means compass direction that a slope faces. The values of aspect are from $4^{\circ}$ to $356^{\circ}$. Below is shown the map (Fig. 10) of aspect created by TIN of QGIS software.

In the same methodology are realized calculating of slope and aspect supported by GRID of QGIS software. This terrain has slope between $4 \%$ to $42 \%$ or $2^{\circ}$ to $22^{\circ}$. And the extreme values of aspect by GRID are $2^{\circ}$ to $345^{\circ}$. Below are generated maps of slope and aspect (Fig. 11a, b, c). From visualization process is reached the perspective view supported by hillshading, contour lines and perspective view that offers QGIS software.
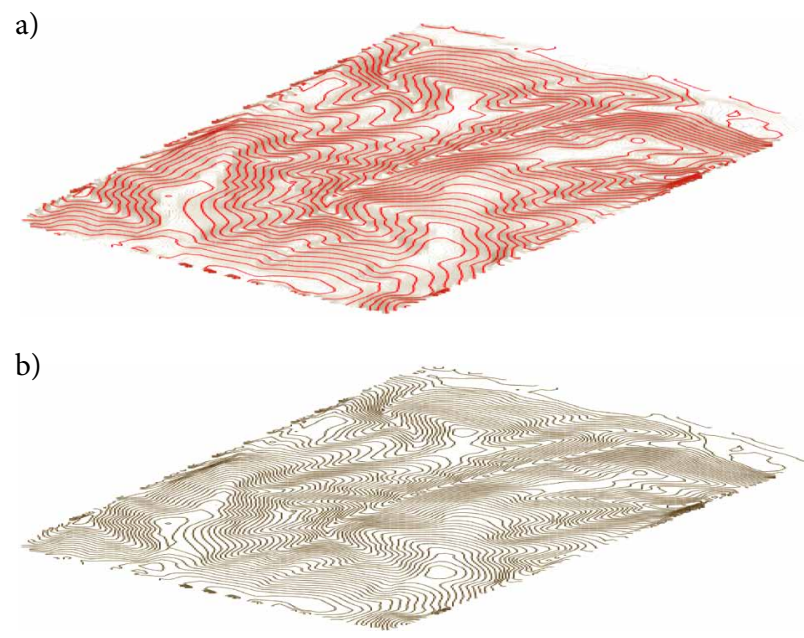

Fig. 7. a) Contour lines (10 m), b) Contour lines (5 m)

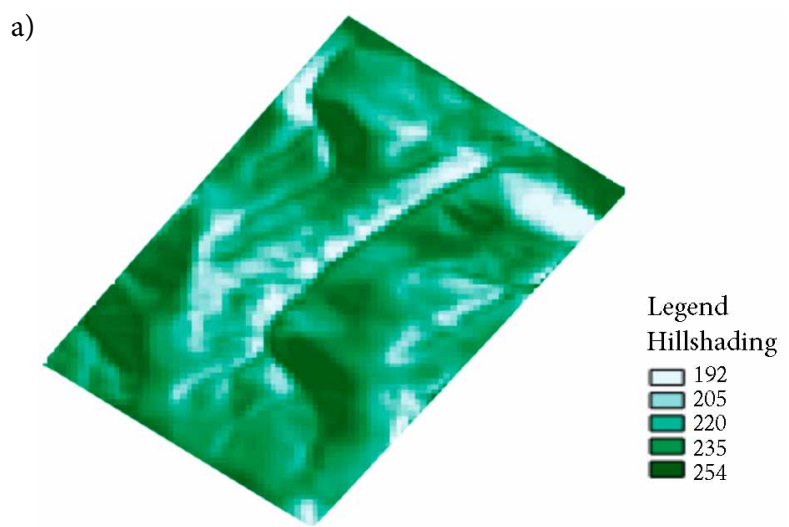

b)

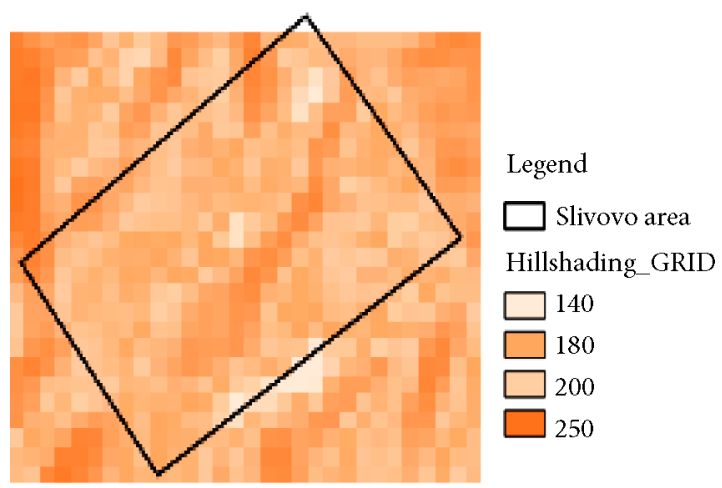

Fig. 8. a) Hillshading of Slivovo area (TIN); b) Hillshading of Slivovo area (GRID)

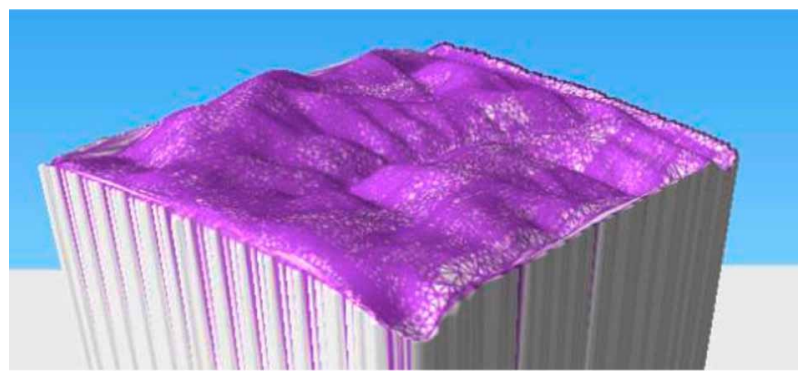

Fig. 9. Perspective view of Slivovo area 
a)

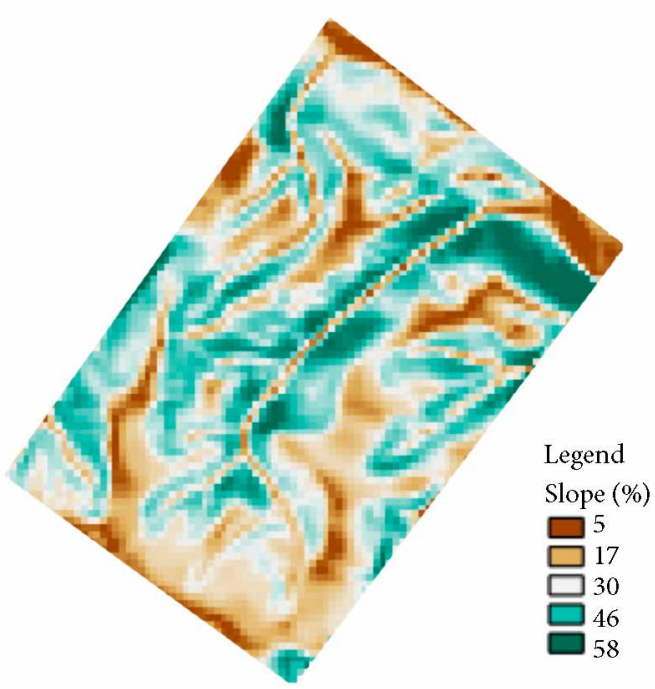

b)

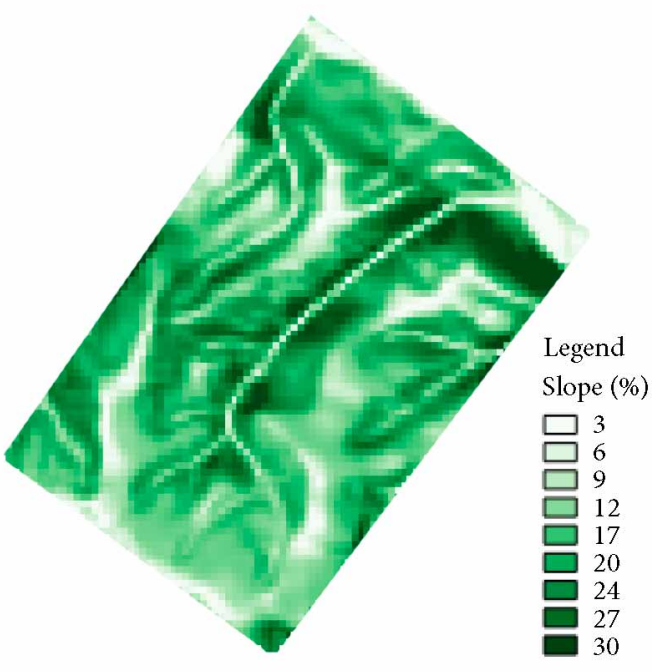

c)

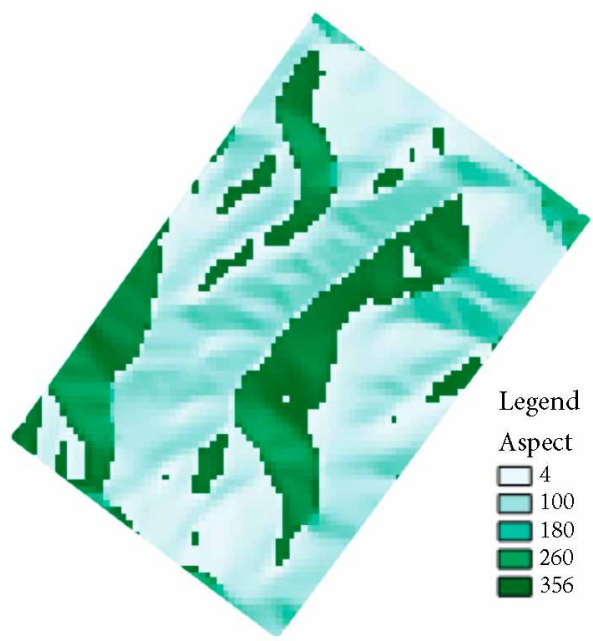

Fig. 10. a) TIN; Slope (\%) ; b) Slope ( ${ }^{\circ}$; c) Aspect (\%)

\section{Conclusions}

Based on paper could be concluded that QGIS software is appropriate software for creating, analysing, intepreting and visualization the DTM and geo-spatial data in general. It is very easy software for generating a)

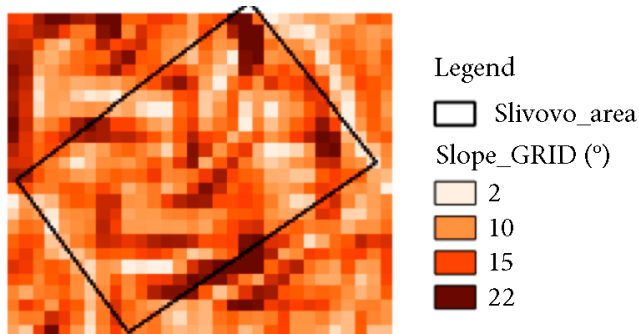

b)

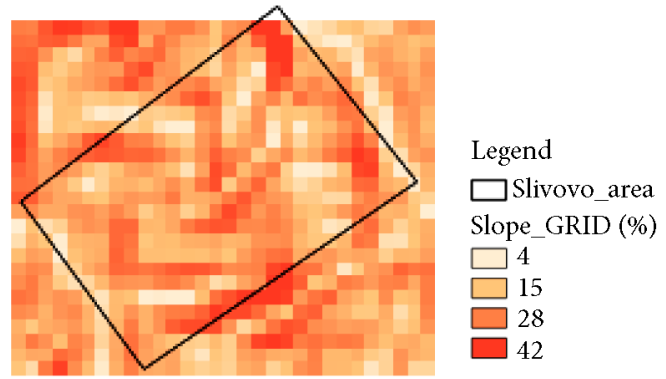

c)

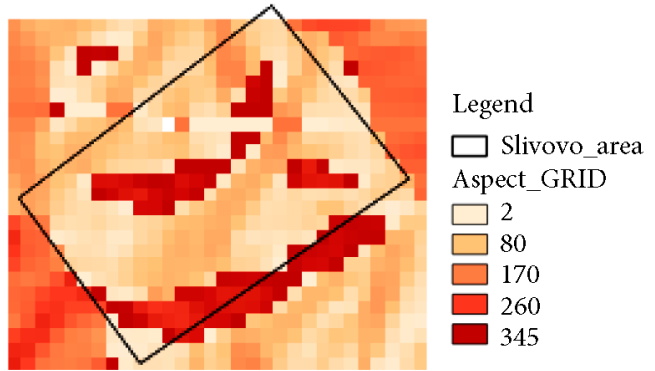

Fig. 11. a) GRID; Slope (\%) ; b) Slope $\left({ }^{\circ}\right)$; c) Aspect (\%)

the DTM. QGIS software supports some methods and techniques of generating DTM. In the paper are proved TIN and GRID methods and some of visualization techniques of DTM like contour lines, hillshading and perspective view. It supports those and offers creating DTM only several clicks. Also QGIS software has sufficient options for DTM creation and analysing landforms in the created DTM. All methods and techniques have advantages and disadvantages between each other. A disadvantage of QGIS software is because this software does not allow/support improving of DTM created for example we can not improve connection of triangles according logical way to TIN. Also it has some choices to visualize the DTM. Based on the paper now we have a clear situation of the Slivovo area and it can use for different reasons. The DTM of Slivovo area could be useful for engineers of all subjects.

\section{References}

El-Heimy, N.; Valeo, C.; Habib, A. 2005. Digital terrain modeling: acquisition, manipulation and applications. Norwood: Artech House. 
Hengel, T.; Gruber, S.; Shrestha, D. P. 2003. Digital terrain analysis in Ilwis. Lecture notes and user guide. International Institute for Geo-Information science, Enschede, The Netherlands, 4-4.

$\mathrm{Hu}, \mathrm{C} .2013$. Comparison of the interpolation methods on digital terrain models: MSc thesis. politecnico di Milano, Milano, Italy.

Osterman, A. 2014. Map visualization in ArcGIS, QGIS and MapInfo. KTH Royal Institute of Technology, Stockholm.

Smuleac, A.; Herbei, M.; Popescu, C. 2012. Creating the digital terrain model of the usamvb area using modern technology, Research Journal of Agricultural Science 44(3): p: 282-287.

Weibel, R.; Heller, M. 1991. Digital terrain modelling, Chapter 19, in D. J. Maguire, M. F. Goodchild, D. W. Rhind (Eds.). Geographical information systems: principles and applications. Wiley, 269-297.

Edon MALIQI, born on 15.08.1988 in Mitrovica, Kosovo. Graduated in department of Geodesy in Faculty of Civil Engineering and Architecture, University of Pristina in 2011. After graduation worked in Kosovo Cadastral Agency a few years as control quality expert position. In 2012 continued in University of Bussines and Technology, department of Geo Information System and Engineering and finished my master in 2014 with thesis "Using of Digital Terrain Model in Civil 3D for calculating volumes in Kelmend landfill”. Developed my carrer in different public institutions and finished some of professional trainings. I am specialized in GIS softwares like Geomedia, ArcGIS, QGIS etc. Assistant professor in the University of Mitrovica "Isa Boletini" in subject of Geo-Information system from 2014 to 2016. Author of a numerous papers in interantional and national scientific journals. From 2016, PhD student in the University of Architecture, Civil Engineering and Geodesy, department of Photogrametry and Cartography in Sofia, Bulgaria, developing my $\mathrm{PhD}$ thesis "Monitoring of Kelmend Landfill by Establishing of Spatial Database and Periodically Serial Compilation of Thematic Maps". Research interests in the field of GIS, Cartography, thematic and Web Mapping.

Petar PENEV, Professor, Dr-eng. at University of Architecture, Civil Engineering and Geodesy - Sofia (UACEG). Head of seven university research projects and two international projects Leonardo da Vinci. Participant in other international projects. Lecturer in Cartography, Thematic Mapping, Web Cartography, Map design and production in UACEG. Research interests in the field of cartography and geographic information systems and mapping the cosmic environment, thematic and Internet mapping.

Faik KELMENDI, born on 25.04.1983 in Obiliq, Kosovo. Graduated in department of Geodesy in Faculty of Civil Engineering and Architecture, University of Pristina . Continoedmy master in Polytechnic University of Tirana, department of Geodesy. Working in Kosovo Cadastral Agency as a head of surveying sector. Developed a carrer in different public instituions and finished some of professional trainings. Specialized in surveying, and GIS. He was engaged in a lot of procejtcs: Developing of 2nd order network and third order network. Transformation the old data form Fryref 30 to Kosovaref01. Manipulating well softwers: Geomedia, Autocad, Leica Geo office, GNSS Spider. Resarch interests in field of geodetic networks, cadastre and GPS. 